\begin{tabular}{|c|c|}
\hline Citation & $\begin{array}{l}\text { Koenraad Muylaert, Leen Bastiaens, Dries Vandamme and Luisa Gouveia } \\
\text { Harvesting of microalgae: overview of process options and their } \\
\text { strengths and drawbacks } \\
\text { Chapter 5, Microalgae-Based Biofuels and Bioproducts, Elsevier Ltd (in } \\
\text { press) }\end{array}$ \\
\hline Archived version & $\begin{array}{l}\text { Author manuscript: the content is identical to the content of the published } \\
\text { paper, but without the final typesetting by the publisher }\end{array}$ \\
\hline Published version & Klik hier als u tekst wilt invoeren. \\
\hline Journal homepage & Klik hier als u tekst wilt invoeren. \\
\hline Author contact & $\begin{array}{l}\text { Koenraad.muylaert@kuleuven.be } \\
\text { Klik hier als u tekst wilt invoeren. }\end{array}$ \\
\hline IR & Klik hier als u tekst wilt invoeren. \\
\hline
\end{tabular}

(article begins on next page) 


\title{
Harvesting of microalgae: overview of process options and their strengths and drawbacks
}

\author{
Koenraad Muylaert ${ }^{1 *}$, Leen Bastiaens ${ }^{2}$, Dries Vandamme ${ }^{1}$ and \\ Luisa Gouveia ${ }^{4}$ \\ ${ }^{1}$ KU Leuven campus Kortrijk, Department Biology, E. Sabbelaan 54, 8500 Kortrijk, \\ Belgium, Tel: +32 56 246283, koenraad.muylaert@kuleuven.be
}

2 Flemish Institute for Technology Research, Boeretang 200, $2400 \mathrm{Mol}$, Belgium, Tel. + +32 14 336924, leen.bastiaens@vito.be

4 LNEG - National Laboratory of Energy and Geology, Bioenergy Unit, Estrada do Paço do Lumiar 22, 1649-038 Lisboa, Portugal, Tel: +351 2109246 00,

luisa.gouveia@Ineg.pt

\section{(NON-PRINTS ITEMS)}

Abstract- Microalgae harvesting is a major challenge because microalgal cells are small and carry a negative surface charge, and biomass concentration in cultures is relatively low. The microalgal biomass $(0.05 \% \mathrm{w} / \mathrm{w})$ needs to be concentrated to a paste with $15-25 \%$ water content. This dewatering process is ideally performed in two stages, including a first pre-concentration step in combination with a second dewatering step. Microalgae are a very heterogenous group of organisms differing in size and shape and culture conditions. Applications of microalgal biomass range from low-value (biofuels) to high-value applications (nutraceuticals). It is therefore likely that the optimal harvesting technology differs between species, culture conditions or the final application of the biomass. Harvesting should not cause contamination of the biomass or influence biomass quality. Finally, water recycling to reduce the water footprint is an important aspect to include into the harvesting process. This chapter gives an overview of several harvesting process options with the focus on their strengths and highlighting the aforementioned aspects.

Keywords - dewatering, coagulation, flocculation, filtration, membrane, centrifugation, flotation

\section{(CHAPTER STARTS HERE)}

\section{$6.1 \quad$ INTRODUCTION}

Microalgae have attracted in the past decade a lot of interest in various industrial applications ranging from biofuels over wastewater treatment to the production of high-value natural products such as pigments or nutritional supplements (e.g. Chisti, 2008; Mata et al., 2010; Park et al., 2011). Nevertheless, production of 
microalgae is still limited to about 10 to 20 thousand ton dry matter per year and the cost of production remains too high for applications such as energy production, feed production or wastewater treatment (Benemann, 2013). One of the main factors that limits the large-scale production of microalgae is the challenge of lowcost biomass harvesting (Brennan and Owende, 2010; Molina Grima et al., 2003; Uduman et al., 2010; Vandamme et al., 2013).

Because microalgae are cultivated as suspension in a liquid medium at a concentration of about $0.5 \mathrm{~g} \mathrm{~L}^{-1}$ or $0.05 \%$, harvesting microalgal biomass requires efficient solid-liquid separation technologies. Because solid-liquid separation is an important unit operation in many production processes, a wide range of technologies are available. These can be divided into two broad categories: methods where particles are separated from the liquid phase based on gravity or buoyancy (sedimentation, flotation, centrifugation) versus methods where the particles are removed from the liquid mechanically by means of a filter or screen. The use of both gravity-based and filtration-based methods is challenging because of the small size of microalgae cells $(5-20 \mu \mathrm{m})$. Flocculation might be combined with gravity- or filtration-based harvesting technologies to aggregate individual microalgal cells into larger particles and thus facilitate separation. Centrifugation is generally the preferred harvesting method in commercial microalgae facilities that target high-value products (Molina Grima et al. 2003). This is a very convenient technology, but it is very costly and energy-demanding, requiring up to $1 \mathrm{MJ} \mathrm{kg}^{-1}$ of dry biomass (Milledge and Heaven, 2012). Several other technologies have been proposed for harvesting microalgae that have a lower cost and energy demand. The aim of this book chapter is to give an overview of all technologies available for harvesting microalgae, and to discuss their advantages and drawbacks.

\subsection{REQUIREMENTS FOR AN EFFECTIVE MICROALGAE HARVESTING TECHNOLOGY}

Production of microalgae has similarities to fermentation as well as agriculture. As in fermentation, microalgae are microorganisms that are cultivated in a liquid medium. Similar to agricultural crops, microalgae require light to grow. The dependence of microalgae on light results in lower biomass concentrations in microalgae production than in fermentation: as microalgal biomass concentration increases in the culture, growth is reduced because of mutual self-shading of the cells. In the open raceway ponds that are today typically used for microalgae production, biomass concentrations are about $0.5 \mathrm{~g} \mathrm{~L}^{-1}$ (Benemann, 2013). This is much lower than in cultures of bacteria, yeasts or even heterotrophic microalgae (e.g. Schizochytrium or Crypthecodinium), where a biomass concentration of $100 \mathrm{~g}$ $\mathrm{L}^{-1}$ can be achieved (Bunch, 1994; Ganuza et al., 2008). As a consequence, in phototrophic production of microalgae, a much larger volume of culture broth needs to be processed to generate the same amount of biomass as in 
heterotrophic production of microorganisms. Any technology for harvesting microalgae should therefore be capable of processing large volumes of culture at a minimal cost and with a minimal energy demand. During harvesting, the culture broth needs to be thickened into a paste with a dry matter content of about $20 \%$ or $200 \mathrm{~g} \mathrm{~L}^{-1}$. As the biomass concentration in the culture broth is generally only about $0.5 \mathrm{~g} \mathrm{~L}^{-1}$, this requires a 400 times up-concentration. The best way to achieve this is by using a combination of two or even more technologies rather than using a single technology (Pahl et al., 2013; Uduman et al., 2010). A distinction can be made between harvesting and dewatering, where harvesting refers to concentration of a culture with a $0.05 \%$ dry matter content to a slurry with a 1 - $5 \%$ dry matter content, and dewatering to the further concentration of that slurry to an algal cake with a 15 - 25 \% dry matter content (Shelef et al., 1984; Uduman et al., 2010).

Microalgae are a heterogenous group of microorganisms that comprises representatives from different evolutionary lines of eukaryotes. As a result, they strongly differ in size, shape, cell rigidity and cell surface properties (e.g. charge, hydrophobicity) (Eldridge et al., 2012). Moreover, microalgae excrete organic matter in the culture medium and the quantity of organic matter that is excreted and its properties also differ between species (R. K. Henderson et al., 2008). The cellular properties of microalgae and the organic matter they excrete in the medium have an important influence on the harvesting of the biomass (e.g. Y.-S. Cheng et al., 2011; Vandamme et al., 2016). These properties of the microalgal cells and the organic matter they excrete in their medium are often influenced by culture conditions. Stationary culture conditions induced by nutrient stress, for instance, can influence the size of microalgal cells (e.g. Fabregas et al., 1985), cell surface properties (e.g. Zhang et al., 2012) or the excretion of organic matter (e.g. Myklestad, 1995), properties that influence harvesting. As a result, it may be necessary to adjust the harvesting strategy to the species of microalgae that is produced, or even to the conditions under which a species is cultured.

The technologies used for harvesting microalgae should not interfere with the final use of the biomass. The microalgal biomass may be used without further processing for a single application (e.g. animal feed, food or a nutritional supplement), or a single product may be extracted from the biomass (e.g. lipids, pigments) while the remaining fraction is a waste product. Opinions today, however, converge on the biorefinery concept, in which the value of the biomass is maximised and waste is minimized by refining the biomass into different components that are used for various applications ranging from energy to animal feed, food or fine chemicals (Gouveia, 2014; Wijffels and Barbosa, 2010). Particularly when the biomass or biomass fractions are used for human or animal consumption, it is important that it is not modified or become contaminated during the harvesting process. Any form of contamination by chemical additives used for harvesting should be avoided, particularly if the chemical additives would trigger alteration of the biomass. 
Production of microalgae also requires very large volumes of water to prepare the culture medium. Most of this water, however, can be recycled after harvesting (Yang et al., 2011). To reduce the water footprint for microalgae biomass production, it is important that the water or spent culture broth is recycled after harvesting. The harvesting technologies that are used should therefore not interfere with the recycling of the culture medium, e.g. by causing contamination of the culture medium. Microalgal cells that escape harvesting may end up in the recycle flow of the culture medium and may be returned to the culture broth. This might lead to selection of those cells that cannot be harvested, e.g. cells that are small enough to pass through a filter or screen, or cells with specific surface properties that avoid flocculation. This selective pressure may result in a gradual decrease in the harvesting efficiency, particularly when microalgae are produced using a continuous culture method (Bull and Collins, 2012). Therefore, it is important that a harvesting method achieves a high recovery efficiency, or that the spent medium is treated after harvesting to remove residual cells before recycling.

\subsection{FLOCCULATION}

\subsubsection{THE POTENTIAL OF FLOCCULATION TO FACILITATE HARVESTING OF MICROALGAE}

During flocculation, numerous individual microalgal cells are aggregated into larger particles called flocs. These flocs can be more easily separated from the culture broth than the individual cells, and this is the case for both gravity-based and filtration-based separation. Spontaneous aggregation of microalgal cells in suspension is prevented by the negative surface charge of the cells. This surface charge is generated by the presence of charged groups on the cell surface, mainly carboxylic acid groups. Because the $\mathrm{pK}_{\mathrm{a}}$ of carboxylic acids is about $4-5$, microalgal cell surfaces are negatively charged down to a pH of about 4 - 5 (Brady et al., 2014; Hadjoudja et al., 2010). The negative surface charge attracts positive ions dissolved in the medium and this results in the formation of a cloud of counterions around the cells. These counterions cause an electrostatic repulsion between the cells. Flocculation can be induced by removing or overcoming this repulsive force. This can be done by addition of chemicals that either neutralize the negative charge on the cell surface (either entirely or in patches), or bind to the surface of multiple cells and form bridges between these cells (Bratby, 2006). Once the electrostatic repulsion between the particles has been offset and the cells can approach each other, they are mutually attracted and held together by Van der Waals forces. An overview of the most common flocculation methods that have been used for harvesting microalgae is given below. 
Flocculation is a widely used technology in different fields of industry such as drinking water production and wastewater treatment from mining. Despite the fact that many off-the-shelf technologies are available, methods that have been successfully used in other industries cannot simply be transferred to microalgae harvesting. The disadvantage of flocculation is that it usually requires the addition of chemicals. In most industrial applications of flocculation, these chemicals end up in the waste sludge that is produced and they are disposed of with this waste. In microalgae harvesting, on the contrary, most of these chemicals end up in the harvested biomass and contaminate the biomass. Therefore, the potential toxicity of the chemicals used for flocculation is critical in microalgae harvesting, much more so than in other industries. The economics are also very different. When flocculation is used to remove impurities from water, the cost is related to the volume of water that is processed rather than the quantity of impurities that is removed. In the case of microalgae harvesting, on the contrary, the cost is related to the amount of biomass that is harvested, and not to the volume of culture broth that is processed.

\subsubsection{METAL SALTS}

Metal salts like aluminum sulphate or ferric chloride are widely used flocculants in different industries. When dissolved in water, the iron or aluminum ions hydrolyse to form positively charged hydroxides that cause flocculation by neutralizing the negative surface charge of particles (Bratby, 2006). At higher dosages, the metal hydroxides form a precipitate that enmeshes particles in suspension and causes them to settle. Flocculation by metal hydroxides has been intensively studied (e.g. Duan and Gregory, 2003). The use of metal salt flocculants in practice, however, has as a disadvantage because it results in contamination of the harvested biomass with relatively high concentrations of metals (Şirin et al., 2012). The counterions of the metals remain in the medium and can interfere with the recycling of the culture medium. Moreover, the dosages that are required are often quite high and $\mathrm{pH}$ adjustment is often needed for the coagulants to work properly, which could also involve a significant cost (Garzon-Sanabria et al., 2012). Nevertheless, metal salts are useful as a model system to understand the fundamental mechanisms of flocculation in microalgae (e.g. Wyatt et al., 2012). Autoflocculation and electro-flocculation are two flocculation methods that function in a somewhat similar way as metal salt flocculants but that have fewer disadvantages (see below).

\subsubsection{AUTOFLOCCULATION}

Autoflocculation is a spontaneous flocculation of microalgae that occurs when the $\mathrm{pH}$ of the culture medium increases. Autoflocculation is a somewhat misleading 
terminology as microalgae do not flocculate by themselves at high $\mathrm{pH}$, but flocculation is rather induced by the precipitation of chemicals which is $\mathrm{pH}$ dependent (González-Fernández and Ballesteros, 2013). In microalgal cultures, the $\mathrm{pH}$ often rises above 8-9 as a result of photosynthetic depletion of $\mathrm{CO}_{2}$. At such alkaline $\mathrm{pH}$ levels, Ca can precipitate as calcium phosphates or calcium carbonates and $\mathrm{Mg}$ can precipitate as magnesium hydroxide or brucite (Brady et al., 2014). This mechanism does not only depend on the $\mathrm{pH}$ but also on the concentration of calcium, magnesium and other ions in solution (e.g. Smith and Davis, 2012). In some conditions, flocculation can occur spontaneously as a result of photosynthetically induced increase in pH (Spilling et al., 2011), in other cases an artificial increase in $\mathrm{pH}$ by addition of bases is required (Vandamme et al., 2012). These precipitates can carry positive charges and cause flocculation by neutralizing the surface charge of microalgal cells or by a sweeping flocculation mechanism. At least in the case of magnesium hydroxide, the flocculation mechanism is probably very similar to that induced by Fe or Al hydroxides (García-Pérez et al., 2014). These calcium or magnesium precipitates are not as toxic as metals and thus cause fewer problems with contamination of the biomass. They can even be removed from the biomass after harvesting by dissolving them by mild acidification (Beuckels et al., 2013; Vandamme et al., 2015).

It is interesting to mention that flocculation of microalgae can also be induced by a decrease in $\mathrm{pH}$. When the $\mathrm{pH}$ of the culture medium is reduced down about 4 , the carboxylic acids on the microalgal cell surface are protonated, the surface charge of microalgal cells becomes neutral and flocculation occurs (Liu et al., 2013).

\subsubsection{ELECTRO-COAGULATION}

Electro-coagulation (EC) has been referred as one of the most effective method for reducing harvesting costs, as it avoids the use of flocculants, uses small electricity amounts, is very fast and efficient (Poelman et al., 1997; Matos et al., 2013; Pacheco et al., 2015). EC has been widely used for the treatment of wastewater (Camcioglu et al., 2014; Bukhari, 2008) and to improve the quality of the drinking water (Alfafara et al., 2002; Poelman et al., 1997). Publications show its efficiency for the removal of small colloidal particles, dyes (Alinsafi et al., 2005), total suspended solids, chemical oxygen demand and turbidity (Inan et al., 2004). For microalgae biomass harvesting from its culture medium, only a few studies have been published (e.g., Xu et al., 2010; Vandamme et al., 2011; Uduman et al., 2011; Matos et al., 2013; Pacheco et al., 2015). In all studies an efficient separation technology, requiring low energy, no flocculant addition and resulting in nor (or a little) secondary contamination of the biomass recovered has been validated.

The EC process is safe, selective, versatile, environmentally sound and cost effective (e.g., Alinsafi et al., 2005). 
During EC, an electrical current is applied through two reactive electrodes (e.g. aluminium or iron electrodes) or through non sacrificial electrodes (Misra et al., 2015; Guldhe et al., 2015), submerged in the microalgae suspension. The anode electrode suffers an electrolytic oxidation producing metal ions that will serve as coagulant agents for the formation of microalga flocs. Furthermore, oxygen and hydrogen microbubbles are generated due to the water oxidation and reduction (Vandamme et al., 2011; Uduman et al., 2011). Both processes combined, allow for the aggregation of cells and easy separation from the culture medium by flotation to the top. However after a certain amount of time, the aggregated cells will drop to the bottom because of their weight.

The recovery efficiency of EC and the saving of energy of EC vs Centrifugation can be depicted from Table 6.1 for some microalgae species.

'TABLE 6.1 HERE' 
Table 6.1. Recovery efficiency and energy savings of electro-coagulation versus centrifugation reported for various algae species

\begin{tabular}{lcc}
\hline Algae & $\begin{array}{c}\text { Recovery } \\
\text { efficiency (\%) }\end{array}$ & $\begin{array}{c}\text { Energy save } \\
\text { (\%) } \\
\text { (vs } \\
\text { centrifugatio } \\
\text { n) }\end{array}$ \\
\hline Nannochloropsis (marine) & 97 & 92 \\
Spirulina & $90(\mathrm{pH}<6)$ & N.A.* \\
& $88(\mathrm{pH}=6)$ & N.A. \\
$\begin{array}{l}\text { Phaeodactylum } \\
\text { tricornutum }\end{array}$ & 78 & 98 \\
$\begin{array}{l}\text { Chlorella vulgaris (fresh } \\
\text { water) }\end{array}$ & 91 & 87 \\
Scenedesmus & 99 & 94.2 \\
Spirogyra & 97 & 90 \\
Synechochystis & 85 & N.A. \\
Neochloris oleabundans & 96 & N.A. \\
\hline
\end{tabular}

$*$ N.A. $=$ Not available

Nonetheless, the aluminium/iron content could generate some toxic effects on the biomass, depending on the current density and operation time. Vandamme et al. (2011) reported $1.5 \%$ of aluminium in the biomass after EC treatment with a current density of $3 \mathrm{~mA} \mathrm{~cm}{ }^{-2}$ over $10 \mathrm{~min}$, while Matos et al. (2013) found a release of $0.56 \%$ and $1.39 \%$ when current density was 3.3 and $8.3 \mathrm{~mA} \mathrm{~cm}^{-2}$, respectively, over $10 \mathrm{~min}$. The electrode depletion not only increases the cost of harvesting but also affects the quality of the recovered biomass. To overcome this limitation, the application of non sacrificial carbon electrodes was suggested by Misra et al. (2015) and Guldhe et al. (2015), by adjusting applied current, $\mathrm{pH}$ and the addition of an electrolyte (sodium chloride).

The energy consumption of EC using non-sacrificial electrodes, claimed by Misra et al. (2015) was $3.384 \mathrm{kWh} \mathrm{kg}^{-1}$, and by Guldhe et al. (2015) $1.76 \mathrm{kWh} \mathrm{kg}^{-1}$, which is lower than other conventional harvesting processes like centrifugation $(65.35 \mathrm{kWh}$ $\mathrm{kg}^{-1}$ ) (Guldhe et al., 2015), chemical flocculation (36.81 $\mathrm{kWh} \mathrm{kg}^{-1}$ ), and filtration (3.58 $\mathrm{kWh} \mathrm{kg}^{-1}$ ) (Danquah et al., 2009; Vandamme et al., 2011). 


\subsubsection{BIOPOLYMER FLOCCULANTS}

Polymer flocculants are polymers with charged functional groups. Polymer flocculants can induce flocculation by neutralising the surface charge of particles or by forming bridges between individual particles. The functional groups should ideally be positively charged to allow for interactions with the negatively charged microalgal cells. Polymers are generally very effective at low dosages. In wastewater treatment, polyacrylamide-based flocculants are commonly used. Because they can contain potentially toxic acrylamide residues, flocculants based on natural biopolymers are preferred over synthetic polymers. An effective biopolymer flocculant for harvesting microalgae is chitosan, which is prepared by deacetylation of chitin. However, the cost of chitosan is relatively high due to its use in medical applications. Cheaper alternatives are cationic starch or tanfloc, which are respectively starch and tannins functionalized with quaternary ammonium groups (Roselet et al., 2016; Vandamme et al., 2010). Important factors that influence the effectiveness of polymer flocculants are the molecular weight of the polymer, the number of functional groups (the charge density) and the charge of the functional groups (Garzon-Sanabria et al., 2012; Roselet et al., 2015).

A disadvantage of polymer flocculants is that they often perform poorly when used for harvesting marine microalgae (Bilanovic et al., 1988). This is due to the high ionic strength of the seawater medium, which causes coiling of the polymers and a decrease in their effective size. This problem does not always occur and sometimes polymer flocculants can be effective in seawater ('t Lam et al., 2014). An alternative may be to use more rigid molecules such as tannin-based flocculants (Roselet et al., 2016) or flocculants based on functionalized nanoparticles, such as nanocellulose (Eyley et al., 2015).

Polymers can be combined with magnetoresponsive $\mathrm{Fe}_{3} \mathrm{O}_{4}$ nanoparticles to separate the flocculated microalgae from the medium in a magnetic field (Lee et al., 2013; Lim et al., 2012; Xu et al., 2011). This magnetic separation is a faster method to separate the flocs from the medium than gravity sedimentation or flotation. When polymers are used to reversibly interact with the microalgal cells (e.g. through $\mathrm{pH}$-responsive charges), the nanoparticles can be recovered from the harvested biomass and re-used (Xu et al., 2011).

\subsubsection{BIOFLOCCULATION}

Bioflocculation is the phenomenon where microalgae flocculate spontaneously or where flocculation is induced by the presence of other microorganisms. Some microalgae tend to flocculate spontaneously, such as for example Ettlia texensis or Pediastrum species (Park et al., 2015; Salim et al., 2014). The mechanisms that are responsible for this phenomenon are often not clearly understood. Mixing of such 
bioflocculating microalgae with non-flocculating microalgae can be used to harvest these other microalgae (Salim et al., 2012). Bio-flocculation can also be induced by addition of other microorganisms. Some bacteria produce extracellular polymers that can induce flocculation of microalgae (e.g. Oh et al., 2001). Filamentous fungi appear to be quite effective in inducing flocculation of microalgae (e.g. Zhou et al., 2013). Bioflocculation often occurs spontaneously in high rate algal ponds used for wastewater treatment. Such ponds are colonized by complex communities of microalgae and bacteria and interactions between species of microalgae or between microalgae and bacteria result in bioflocculation, although the mechanisms are often not clearly understood (Posadas et al., 2014; Van Den Hende et al., 2011). Bioflocculation is therefore a promising simple flocculation method in microalgae-bacteria wastewater treatment systems (Craggs et al., 2012).

\subsection{GRAVITY-BASED TECHNOLOGIES}

\subsubsection{GRAVITY SETTLING}

Harvesting by gravity sedimentation is a very attractive option because it requires very little energy and relatively low-cost infrastructure. Sedimentation can be carried out in simple settling tanks, but these usually have a relatively large footprint (Figure 6.1, A). Inclined settlers or lamella separators consist of a series of stacked plates, which increases the effective area available for settling and reduces the footprint (Figure 6.1, B). Gravity sedimentation is a relatively slow process and this may result in deterioration of the biomass quality during harvesting. Gravity sedimentation also generates a rather dilute slurry and should therefore be primarily used as an initial concentration mechanism to pre-concentrate the biomass prior to complete dewatering using another technology such as centrifugation or filtration.

The settling rate is a critical parameter to harvest microalgae using gravity sedimentation. Stokes' law dictates that the settling rate increases with the square of the size of the microalgae and their difference in density with the medium. Because most microalgae are small $(<20 \mu \mathrm{m})$ and have a density that is very close to that of water, they have a very low intrinsic settling velocity of about $1 \mathrm{~cm} \mathrm{~h}^{-1}$. This is too low to concentrate the biomass using conventional gravitational settlers. The exception are relatively large microalgae with a high specific density, or microalgae that form aggregates. For instance, Algatech (Israel) used gravity sedimentation to harvest astaxanthin-rich Haematococcus cysts (oral communication, Algatech). Because the process was too slow and resulted in a deterioration of biomass quality, however, they later switched to centrifugation as a harvesting method. Gravity sedimentation can also be used to harvest Arthrospira filaments that have accumulated glycogen. Because glycogen has a high specific density (about $1.5 \mathrm{~g} \mathrm{~g} \mathrm{~g}^{-1}$ ) and Arthrospira can accumulate large 
amounts of it (> $50 \%$ under nitrogen limited conditions), such filaments can have a settling rate of $64 \mathrm{~cm} \mathrm{~h}^{-1}$ and can theoretically be harvested by gravity sedimentation (Depraetere et al., 2015). Because the microalgae Scenedesmus forms natural aggregates, it can also be harvested by gravity sedimentation (Wang et al., 2014). Smith and Davis (2013) showed that it may also be feasible to concentrate microalgae with a low settling rate using inclined settlers if these have a low angle and a high aspect ratio.

Gravity sedimentation is the straightforward method of solid-liquid separation to be used in combination with flocculation. Flocculation should ideally result in large flocs that settle fast generate a compact sludge (Smith and Davis, 2012; Vandamme et al., 2014). A high settling rate is essential to have a fast harvesting procedure and to avoid deterioration of the biomass. A compact sludge allows for a significant up-concentration of the biomass to a dense slurry that can be further dewatered using centrifugation or filtration. Although there have been many studies on flocculation of microalgae, relatively few have evaluated to the potential to concentrate the flocculated microalgae using gravity sedimentation, either in simple settling tanks or using inclined settlers. Most research so far has been carried out using bio-flocculated microalgae harvested from high rate algal ponds (Craggs et al., 2012; Nurdogan and Oswald, 1996).

'FIGURE 6.1 HERE'

Figure 6.1. Principles of separation of flocculated microalgae from the clarified culture medium using a settling basin (A), a lamella separator (B) and dissolved air flotation (C).

\subsubsection{CENTRIFUGATION}

Centrifugation can be considered as a method for enhanced settling. It is the most widely used harvesting technology in production facilities that produce microalgae for high-value products. Different types of industrial centrifuges are available. A disc bowl centrifuge is used for suspension with a low solids content (from $0.01 \%$ to $20 \%$ algal dry weight) while a decanter centrifuge is used for suspension with a higher solids content (from $10 \%$ to $50 \%$ algal dry weight) (Milledge and Heaven, 2012). Both can be operated continuously. Harvesting by centrifugation has many advantages: there is no need to add chemicals during the process, a high dry matter content can be achieved in a single-step process and it is fast and thus avoids deterioration of biomass quality. The disadvantage is that the investment cost for large centrifuges is very high and that centrifuges have a high energy demand. Some approaches have been proposed to reduce the energy demand of centrifugation. Evodos (The Netherlands) have designed a centrifuge with spiral plates which reduces the distance travelled by a settling microalgae and increases the surface area. Significant energy savings can be achieved by increasing the flow rate through the centrifuge. Although this results in a lower harvesting efficiency, the energy consumption per unit of biomass harvested is significantly reduced (Dassey and Theegala, 2013). 
Although centrifugation should be replaced by more energy-efficient harvesting methods, particularly when microalgae are produced for low-value applications, it will probably continue to play an important role in the final dewatering of microalgal slurries that are produced after primary concentration using flocculation/sedimentation, flocculation/flotation or membrane filtration because centrifugation can provide a thick paste with a high dry matter content (Shelef et al., 1984). Preconcentration of the biomass results in a reduction in the volume of culture that needs to be processed by at least an order of magnitude and, as a result, the energy demand for centrifugation will also be much lower. Moreover, because flocculation results in an increase in particle size, the centrifugal forces required to separate the biomass from the medium are much lower than for individual cells.

\subsubsection{FLOTATION}

In flotation, small air bubbles interact with microalgal and carry the cells to the water surface, where they form a scum that can be skimmed off. In dissolved air flotation, the air bubbles are formed by mixing water that is supersaturated with air into the culture (Figure $6.1, \mathrm{C}$ ). It uses a return flow of clarified water that is mixed with air under high pressure. In dispersed air flotation, air bubbles are formed by releasing pressurised air through a nozzle or through porous media. Dissolved air flotation tends to perform better than dispersed air flotation because the bubbles that are formed are smaller, but the energy demand is also higher. Electrolysis can be used to generate hydrogen bubbles for flotation. This latter approach works better for marine than freshwater microalgae due to the higher electrical conductivity of seawater (Sandbank and Shelef, 1987).

Flotation depends on the interaction between microalgal cells and air bubbles. Because both air bubbles and microalgal cells are negatively charged, they do not interact and flotation generally does not work well for harvesting microalgae unless additives are used (Garg et al., 2012). Flotation can be improved by the addition of surfactants (Coward et al., 2013; Rita K. Henderson et al., 2008). In dispersed ozone flotation, ozone is used as a carrier gas rather than air. It is believed that ozone modifies the microalgal cell wall and reduces the charge, resulting in better adhesion of microalgal cells to gas bubbles (Y.-L. Cheng et al., 2011). Flotation is often used in combination with flocculation (Besson and Guiraud, 2013; Kwon et al., 2014). The use of flotation to concentrate flocculated microalgal suspensions has some advantages over gravity sedimentation. High biomass concentrations can be achieved in the froth that is skimmed from the surface. Moreover, flotation is a much faster separation method than gravity sedimentation, and therefore there is a lower risk of deterioration of biomass quality during harvesting. 


\subsection{FILTRATION-BASED SEPARATION TECHNOLOGIES}

Filtration refers to a mechanical or physical process to separate solids from water or gases (fluids) by interposing a permeable separator, like screens, filter cloths or permeable membranes, which retains solids. The driving force of active filtration is a pressure drop across the barrier created via vacuum, pressure or gravity. Shelef et al. (1984) described multiple filtration devices including pressure filters (like plate-and-frame press) and vacuum filters (like leaf or Moor filters, Nutsche filters, belt filters, rotary filters), cartridge filters, deep-bed filtration as well as cross-flow filtration. Other approaches include submerged membrane filtration, rotating disks, vibrating/rotating membranes and passive filtration via osmosis (Mo et al., 2015). By altering the characteristics of the permeable separator different types of solids are retained, while others pass with the fluid through the permeable barrier into the filtrate. Most commonly, the pore sizes of the separator are used to create a cut-off based on particle size or molecular weight (Drexler and Yeh, 2014). For membrane filters a distinction can be made between macro-filtration (pore size $>10 \mu \mathrm{m}$ ), micro-filtration $(0.1-10 \mu \mathrm{m})$ and ultra-filtration $(0.001-0.10 \mu \mathrm{m})$. Further, functionalized separators have been reported (Mustafa et al., 2014) that also enable fractionation based on for instance surface charge and hydrophobicity.

Filtration is attractive for algae harvesting because of its recovery efficiencies, its ability to separate shear sensitive species, and separation without addition of chemicals avoiding contamination of the biomass and allowing reuse of the permeate (Al Hattab et al., 2015; Barros et al., 2015; Mo et al., 2015). On the other hand, points of attention can be clogging and fouling, cleaning processes for the membranes and investment costs for membranes and pumps. A lack of knowledge of the most relevant operating conditions has been reported. Concerning algae harvesting, filtration can be used for different purposes including algae harvesting, dewatering, and water recirculation.

\subsubsection{SCREENING OF LARGER SIZED MICRO-ALGAE}

Despite the fact that screening is a solid-solid separation method (Shelef et al. 1984), it can be used for harvesting larger sized algae like Cyanobacteria Spirulina $(1-10 \mu \mathrm{m})$ that form filaments (100-200 $\mu \mathrm{m}$ in length; $10-20 \mu \mathrm{m}$ in diameter). Especially the intertwined filaments can be harvested on the spot using screens. Aphanizomenon flos-aqua is another member of the Cyanobacteria that grows in natural lakes. The principle as screening is introducing particles of a given size. Carmichael et al. (2000) reported the use of screens made of nylon for harvesting 
these algae from surface water. Vertical debris screens (0.6 to $1.2 \mathrm{~cm}$ in mesh size) were used upstream of the harvesting area to retain fish and flotsam, followed by multiple sets (up to 48) of alga collecting screens. The latter were also made of nylon $\left(20 \mathrm{~m}^{2}\right)$ and were position nearly horizontally. Water passed through the screens while the algae remained on top of the screens. Algae were removed from the screens using water sprays.

\subsubsection{HARVESTING OF ALGAE VIA MEMBRANE FILTRATION}

Although macro-filtration is suitable for large microalgae cells or flocculated algal biomass (Al Hattab et al., 2015), micro- and ultrafiltration are the most commonly studied membrane types for microalgae filtration. Both are able to retain the microalgae by nearly $100 \%$ (Drexler and Yeh, 2014). While microfiltration generally allows higher fluxes at short term, ultrafiltration has been reported to perform better at longer term due to higher fouling resistance (Baerdemaeker et al., 2013; Danquah et al., 2009; Rossignol et al., 1999). The capacity of a filtration unit is mainly determined by the fluxes that can be achieved and the amount of algae biomass that can be retained. Fluxes are expressed as volume of permeate per unit of time per unit membrane surface $\left(\mathrm{L} \mathrm{h}^{-1} \mathrm{~m}^{-2}\right)$ and are influenced by algae species, cell density of algae, cell integrity, transmembrane pressure, cross-flow velocity, membrane type, pore size, and composition of the medium (Al Hattab et al., 2015; Mo et al., 2015). Fouling negatively influences flux-values and is due to membrane/solutes interactions and cake formation. Parameters like membrane pore size, particles size, surface charge, hydrophobicity of the membrane and the composition of the medium highly influence fouling (Drexler and Yeh, 2014; Rossignol et al., 1999). Extracellular polymeric substances (EPS) like polysaccharides and intracellular products released after cell disruption contribute to fouling. Rickman et al. (2012) reported the importance of submicron particles as primary foulants. Fouling can be partially controlled by generating turbulent flow near the membrane surface, bubbling, backwashing or chemical cleaning (Drexler and Yeh, 2014), but irreversible fouling may occur especially with hydrophobic membranes and/or hydrophobic EPS (Mustafa et al., 2014; Rossignol et al., 1999). In terms of energy use, Mo et al (2015) concluded that membrane filtration (0.17-2 $\mathrm{kWh} \mathrm{m}^{-3}$ ) can be very competitive compared to alternative technologies.

'FIGURE 6.2 HERE'

Figure 6.2 - Different membrane filtration configurations.

Figure 6.2 depicts a number of active filtration configurations that have different fluid and particles flows across/along the membrane. In case of dead-end or conventional filtration (Figure 6.2, A), the water flow is perpendicular to the filter and all particles are forced to settle on the filter surface. Particles can only be 
removed by backwashing and/or replacement of the filter medium. Because of fouling, dead-end filtrations is mainly applied for filtering low concentrated solutions. Although effective for large microalgae cells $(>70 \mu \mathrm{m})$ like Coelastrum and Spirulina species (Barros et al., 2015; Shelef et al., 1984), dead-end filtration is considered not economically viable for most microalgae harvesting purposes. Cross-flow filtration or tangential flow filtration (Figure 6.2, B) is less susceptible to fouling as, while the permeate passes through the filter, the feed solution flows parallel to the filter surface generating shear stress that reduces the filter cake thickness and keeps the algal biomass more in suspension. The cells in the retentate are kept in the system by recirculating the retentate across the membrane. According to data collected by Mo et al. (2015) from multiple studies with different algae species and diverse membranes types, for cross-flow filtration with an initial algae concentration of 0.04-2 $\mathrm{g} \mathrm{L}^{-1}$, fluxes varied between 13 and 150 $\mathrm{L} \mathrm{hm}^{-2}$ and volume reduction factors of 5-154 were reported. Achievable final algae contents are $8.8-15.5 \%$. By increasing the cross-flow velocity, fouling can be reduced enabling higher fluxes (Rossignol et al., 1999). On the other hand, shear forces induce stress in algae biomass and may result in a release of algogenic compounds and even cell disruption that increase fouling and economic losses. Submerged membrane filtration (Figure 6.2, C) refers to a more recent approach where membrane bags connected to a vacuum pump are placed directly in the algal culture (Mo et al., 2015). Backwashable flat screen membrane envelope loops, an integrated permeate channel (IPC) concept (Doyen et al., 2008), have been used as well as non-backwashable membranes (Baerdemaeker et al., 2013; Bilad et al., 2012) and magnetic vibrating of the membranes (Bilad et al., 2013). Depending on the initial algae density, volume reduction factors of 5 to 20 are reported (Mo et al. 2015) with a final algal concentration of 5-150 $\mathrm{g} \mathrm{L}^{-1}$. Critical fluxes range from 10 to $50 \mathrm{~L} \mathrm{~h}^{-1} \mathrm{~m}^{-2}$. Passive filtration techniques like forward osmosis have also been evaluated for harvesting freshwater algae and are associated with a low energy cost. Water is drawn from the algae suspension by concentration gradients using seawater (Buckwalter et al., 2013).

Although considerable final algal concentrations can be achieved technically at small scale, membrane-based technologies may have their main merits as preconcentration step at larger scale. As fluxes drastically decrease with higher cell densities (Rossignol et al. 1999), high energy input, long processing times and/or large membrane surface areas may be required to reach these cell densities. Alternatively, the major part of the water can be removed via membrane filtration as pre-concentration step (up to 2-7 \%) followed by further concentration of the algae biomass (up to 20-25\%) using other technologies including centrifugation (De Baerdemaker et al. 2013; Buckwalter et al. 2013; Bilad et al. 2012; 2013) and other filtration approaches. The latter includes the discontinuous but very reliable chamber press filtration (up to 22\%) (Mo et al. 2015; Grima et al. 2003). 
Microalgae cultivation is a water intensive process requiring in raceways $1000 \mathrm{~L}$ of water per $\mathrm{kg}$ of biomass (Guieysse et al., 2013) and up to $3360 \mathrm{~L}$ of water per $\mathrm{L}$ biodiesel (Farooq et al., 2015). Reduction of evaporation and implementation of water recycling can drastically reduce the water use (up to $>85 \%$ ). Membrane filtration has not only been proven to be competitive for surface water and wastewater treatment before its use in algae cultivation systems, but also offers potential for recycling water after algae growth for reuse in the cultivation system (Drexler and Yeh, 2014). Membranes can remove turbidity and algal or bacterial contamination from the water, while leaving dissolved nutrients in solution for reuse. Different water recycling approaches can be distinguished. After the harvesting step, the algae-free medium can be polished and disinfected via microfiltration or ultrafiltration. Another approach is the integration of the water recycling step into a membrane based (pre-) harvesting step. During such a preconcentration step, $80 \%$ and $90 \%$ of the water can be recycled with a volume reduction factor of 5 and 10, respectively. A techno-economic assessment study indicated that recycling of water in a raceway scenario reduced the salt and water use five-fold, and reduced the amount of wastewater, required energy and heat, leading to an overall reduction of CAPEX and OPEX by $4 \%$ and $41 \%$, respectively (Thomassen et al., 2016).

\subsection{CONCLUSIONS/SUMMARY/COMPARISON OF METHODS}

Developing a low-cost and energy-efficient harvesting method remains one of the major challenges to achieve large-scale production of microalgae. During microalgal harvesting, the biomass needs to be upconcentrated 400 times from a dilute culture with a biomass concentration of $0.05 \%$ to a microalgal paste with a dry matter content of $15-25 \%$. This is probably best done in a two stage process. One example could be membrane filtration to pre-concentrate the biomass combined with centrifugation to obtain an algal paste. Another example is flocculation combined with a lamella settler followed by dewatering of the sludge using a filter press. Because microalgae are a very heterogeneous group of organisms, it is likely that different species require a different approach for harvesting. Care should be taken that harvesting does not result in contamination (e.g. as a result of addition of a chemical flocculant) or damage (e.g. as a result of shear forces) to the biomass. The amount of contamination or damage that is acceptable depends on the final use of the biomass, and therefore the choice of the harvesting method will depend on the biomass application. Finally, to reduce the water footprint, it is also important that the harvesting method allows re-use of the spent culture medium. 


\subsection{REFERENCES}

't Lam, G.P., Vermuë, M.H., Olivieri, G., van den Broek, L. a. M., Barbosa, M.J., Eppink, M.H.M., Wijffels, R.H., Kleinegris, D.M.M., 2014. Cationic polymers for successful flocculation of marine microalgae. Bioresource Technology 169, 804-807.

Al Hattab, M., Ghaly, A., Hammoud, A., 2015. Microalgae Harvesting Methods for Industrial Production of Biodiesel: Critical Review and Comparative Analysis. Journal of Fundamentals of Renewable Energy and Applications 5, 1000154.

Alfafara, C.G., Nakano, K., Nomura, N., Igarashi, T., Matsumura, M., 2002. Operating and scale-up factors for the electrolytic removal of algae from eutrophied lakewater. Journal of Chemical Technology \& Biotechnology 77, 871-876.

Alinsafi, A., Khemis, M., Pons, M.N., Leclerc, J.P., Yaacoubi, A., Benhammou, A., Nejmeddine, A., 2005. Electro-coagulation of reactive textile dyes and textile wastewater. Chemical Engineering and Processing: Process Intensification 44, 461-470.

Baerdemaeker, T. De, Lemmens, B., Dotremont, C., Fret, J., Roef, L., Goiris, K., Diels, L., 2013. Benchmark study on algae harvesting with backwashable submerged flat panel membranes. Bioresource Technology 129, 582-591.

Barros, A.I., Gonçalves, A.L., Simões, M., Pires, J.C.M., 2015. Harvesting techniques applied to microalgae: A review. Renewable and Sustainable Energy Reviews $41,1489-1500$.

Benemann, J., 2013. Microalgae for Biofuels and Animal Feeds. Energies 6, 58695886.

Besson, A., Guiraud, P., 2013. High-pH-induced flocculation-flotation of the hypersaline microalga Dunaliella salina. Bioresource Technology 147C, 464470.

Beuckels, A., Depraetere, O., Vandamme, D., Foubert, I., Smolders, E., Muylaert, K., 2013. Influence of organic matter on flocculation of Chlorella vulgaris by calcium phosphate precipitation. Biomass and Bioenergy 54, 107-114.

Bilad, M.R., Discart, V., Vandamme, D., Foubert, I., Muylaert, K., Vankelecom, I.F.J., 2013. Harvesting microalgal biomass using a magnetically induced membrane vibration (MMV) system: Filtration performance and energy consumption. Bioresource Technology 138, 329-338.

Bilad, M.R., Vandamme, D., Foubert, I., Muylaert, K., Vankelecom, I.F.J., 2012. Harvesting microalgal biomass using submerged microfiltration membranes. Bioresource Technology 111, 343-52.

Bilanovic, D., Shelef, G., Sukenik, A., 1988. Flocculation of microalgae with cationic polymers - Effects of medium salinity. Biomass 17, 65-76.

Brady, P. V., Pohl, P.I., Hewson, J.C., 2014. A coordination chemistry model of algal autoflocculation. Algal Research 5, 226-230.

Bratby, J., 2006. Coagulation and flocculation in water and wastewater treatment. IWA Publishing, London, UK. 
Brennan, L., Owende, P., 2010. Biofuels from microalgae-A review of technologies for production, processing, and extractions of biofuels and co-products. Renewable and Sustainable Energy Reviews 14, 557-577.

Buckwalter, P., Embaye, T., Gormly, S., Trent, J.D., 2013. Dewatering microalgae by forward osmosis. Desalination 312, 19-22.

Bukhari, A.A., 2008. Investigation of the electro-coagulation treatment process for the removal of total suspended solids and turbidity from municipal wastewater. Bioresource Technology 99, 914-921.

Bull, J.J., Collins, S., 2012. Algae for biofuel: Will the evolution of weeds limit the enterprise? Evolution 66, 2983-2987.

Bunch, A., 1994. High Cell Density Growth of Microorganisms. Biotechnology and Generic Engineering Reviews 12, 535-561.

Camcioglu, S., Canan Pekel, L., Polat, K., Hapoglu, H., 2014. Experimental design of wastewater treatment with electro-coagulation. Management of Environmental Quality: An International Journal 25, 86-95.

Carmichael, W.W., Drapeau, C., Anderson, D.M., 2000. Harvesting of Aphanizomenon flos-aquae Ralfs ex Born. \& Flah. var. flos-aquae (Cyanobacteria) from Klamath Lake for human dietary use. Journal of Applied Phycology 12, 585-895.

Cheng, Y.-L., Juang, Y.-C., Liao, G.-Y., Tsai, P.-W., Ho, S.-H., Yeh, K.-L., Chen, C.-Y., Chang, J.-S., Liu, J.-C., Chen, W.-M., Lee, D.-J., 2011. Harvesting of Scenedesmus obliquus FSP-3 using dispersed ozone flotation. Bioresource technology 102, 82-7.

Cheng, Y.-S., Zheng, Y., Labavitch, J.M., VanderGheynst, J.S., 2011. The impact of cell wall carbohydrate composition on the chitosan flocculation of Chlorella. Process Biochemistry 46, 1927-1933.

Chisti, Y., 2008. Biodiesel from microalgae beats bioethanol. Trends in Biotechnology 26, 126-31.

Coward, T., Lee, J.G.M., Caldwell, G.S., 2013. Development of a foam flotation system for harvesting microalgae biomass. Algal Research 1-10.

Craggs, R., Sutherland, D., Campbell, H., 2012. Hectare-scale demonstration of high rate algal ponds for enhanced wastewater treatment and biofuel production. Journal of Applied Phycology 24, 329-337.

Danquah, M.K., Ang, L., Uduman, N., Moheimani, N., Forde, G.M., 2009. Dewatering of microalgal culture for biodiesel production: exploring polymer flocculation and tangential flow filtration. Journal of Chemical Technology \& Biotechnology 84, 1078-1083.

Dassey, A.J., Theegala, C.S., 2013. Harvesting economics and strategies using centrifugation for cost effective separation of microalgae cells for biodiesel applications. Bioresource technology 128, 241-5.

Depraetere, O., Pierre, G., Deschoenmaeker, F., Badri, H., Foubert, I., Leys, N., Markou, G., Wattiez, R., Michaud, P., Muylaert, K., 2015. Harvesting carbohydrate-rich Arthrospira platensis by spontaneous settling. Bioresource Technology 180, 16-21. 
Doyen, W., Becker, H., Adriansens, W., Dotremont, C., 2008. Integrated permeate channel membrane. US 20100322867A1.

Drexler, I.L.C., Yeh, D.H., 2014. Membrane applications for microalgae cultivation and harvesting: a review. Reviews in Environmental Science and Biotechnology.

Duan, J., Gregory, J., 2003. Coagulation by hydrolysing metal salts. Advances in Colloid and Interface Science 100-102, 475-502.

Eldridge, R.J., Hill, D.R. a., Gladman, B.R., 2012. A comparative study of the coagulation behaviour of marine microalgae. Journal of Applied Phycology 24, 1667-1679.

Eyley, S., Vandamme, D., Lama, S., Van den Mooter, G., Muylaert, K., Thielemans, W., 2015. CO 2 controlled flocculation of microalgae using $\mathrm{pH}$ responsive cellulose nanocrystals. Nanoscale 7, 14413-14421.

Fabregas, J., Herrero, C., Cabezas, B., Abalde, J., 1985. Mass culture and biochemical variability of the marine microalga Tetraselmis suecica Kylin (Butch) with high nutrient concentrations. Aquaculture 49, 231-244.

Farooq, W., Suh, W.I., Park, M.S., Yang, J.W., 2015. Water use and its recycling in microalgae cultivation for biofuel application. Bioresource Technology 184, 7381.

Ganuza, E., Anderson, A.J., Ratledge, C., 2008. High-cell-density cultivation of Schizochytrium sp. in an ammonium/pH-auxostat fed-batch system. Biotechnology Letters 30, 1559-1564.

García-Pérez, J.S., Beuckels, A., Vandamme, D., Depraetere, O., Foubert, I., Parra, R., Muylaert, K., 2014. Influence of magnesium concentration, biomass concentration and $\mathrm{pH}$ on flocculation of Chlorella vulgaris. Algal Research 3, 24-29.

Garg, S., Li, Y., Wang, L., Schenk, P.M., 2012. Flotation of marine microalgae: effect of algal hydrophobicity. Bioresource technology 121, 471-4.

Garzon-Sanabria, A.J., Davis, R.T., Nikolov, Z.L., 2012. Harvesting Nannochloris oculata by inorganic electrolyte flocculation: effect of initial cell density, ionic strength, coagulant dosage, and media pH. Bioresource Technology 118, 41824.

González-Fernández, C., Ballesteros, M., 2013. Microalgae autoflocculation: an alternative to high-energy consuming harvesting methods. Journal of Applied Phycology 25, 991-999.

Gouveia, L., 2014. From Tiny Microalgae to Huge Biorefineries. Oceanography: Open Access 02, 2-9.

Guieysse, B., Béchet, Q., Shilton, A., 2013. Variability and uncertainty in water demand and water footprint assessments of fresh algae cultivation based on case studies from five climatic regions. Bioresource Technology 128, 317-323.

Guldhe, A., Misra, R., Singh, P., Rawat, I., Bux, F., 2015. An innovative electrochemical process to alleviate the challenges for harvesting of small size microalgae by using non-sacrificial carbon electrodes. Algal Research, doi:10.1016/j.algal.2015.08.014 
Hadjoudja, S., Deluchat, V., Baudu, M., 2010. Cell surface characterisation of Microcystis aeruginosa and Chlorella vulgaris. Journal of Colloid and Interface Science 342, 293-9.

Henderson, R.K., Parsons, S.A., Jefferson, B., 2008. The impact of algal properties and pre-oxidation on solid-liquid separation of algae. Water Research 42, 182745.

Henderson, R.K., Parsons, S.A., Jefferson, B., 2008. Surfactants as bubble surface modifiers in the flotation of algae: Dissolved air flotation that utilizes a chemically modified bubble surface. Environmental Science and Technology 42, 4883-4888.

Inan, H., Dimoglo, A., ??im??ek, H., Karpuzcu, M., 2004. Olive oil mill wastewater treatment by means of electro-coagulation. Separation and Purification Technology 36, 23-31.

Kwon, H., Lu, M., Lee, E.Y., Lee, J., 2014. Harvesting of microalgae using flocculation combined with dissolved air flotation. Biotechnology and Bioprocess Engineering 19, 143-149.

Lee, K., Lee, S.Y., Na, J.G., Jeon, S.G., Praveenkumar, R., Kim, D.M., Chang, W.S., Oh, Y.K., 2013. Magnetophoretic harvesting of oleaginous Chlorella sp. by using biocompatible chitosan/magnetic nanoparticle composites. Bioresource Technology 149, 575-578.

Lim, J., Chieh, D.C.J., Jalak, S.A., Toh, P.Y., Yasin, N.H.M., Ng, B.W., Ahmad, A.L., 2012. Rapid magnetophoretic separation of microalgae. Small 8, 1683-92.

Liu, J., Zhu, Y., Tao, Y., Zhang, Y., Li, A., Li, T., Sang, M., Zhang, C., 2013. Freshwater microalgae harvested via flocculation induced by $\mathrm{pH}$ decrease. Biotechnology for biofuels 6, 98.

Mata, T.M., Martins, A.A., Caetano, N.S., 2010. Microalgae for biodiesel production and other applications: A review. Renewable and Sustainable Energy Reviews 14, 217-232.

Matos, C.T., Santos, M., Nobre, B.P., Gouveia, L., 2013. Nannochloropsis sp. biomass recovery by Electro-Coagulation for biodiesel and pigment production. Bioresource Technology 134, 219-226.

Milledge, J.J., Heaven, S., 2012. A review of the harvesting of micro-algae for biofuel production. Reviews in Environmental Science and Biotechnology 12, 165-178.

Misra, R., Guldhe, A., Singh, P., Rawat, I., Stenström, T.A., Bux, F., 2015. Evaluation of operating conditions for sustainable harvesting of microalgal biomass applying electrochemical method using non sacrificial electrodes. Bioresource technology 176, 1-7.

Mo, W., Soh, L., Werber, J.R., Elimelech, M., Zimmerman, J.B., 2015. Application of membrane dewatering for algal biofuel. Algal Research 11, 1-12.

Molina Grima, E., Belarbi, E.H., Acién Fernández, F.G., Robles Medina, A., Chisti, Y., 2003. Recovery of microalgal biomass and metabolites: process options and economics. Biotechnology Advances 20, 491-515. 
Mustafa, G., Wyns, K., Vandezande, P., Buekenhoudt, A., Meynen, V., 2014. Novel grafting method efficiently decreases irreversible fouling of ceramic nanofiltration membranes. Journal of Membrane Science 470, 369-377.

Myklestad, S.M., 1995. Release of extracellular products by phytoplankton with special emphasis on polysaccharides. Science of the Total Environment 165, 155-164.

Nurdogan, Y., Oswald, W.J., 1996. Tube settling of high-rate pond algae. Water Science and Technology 33, 229-241.

Oh, H.M., Lee, S.J., Park, M.H., Kim, H.S., Kim, H.C., Yoon, J.H., Kwon, G.S., Yoon, B.D., 2001. Harvesting of Chlorella vulgaris using a bioflocculant from Paenibacillus sp. AM49. Biotechnology Letters 23, 1229-1234.

Pacheco, R., Ferreira, A.F., Pinto, T., Nobre, B.P., Loureiro, D., Moura, P., Gouveia, L., Silva, C.M., 2015. The production of pigments \& hydrogen through a Spirogyra sp. biorefinery. Energy Conversion and Management 89, 789-797.

Pahl, S.L., Lee, A.K., Kalaitzidis, T., Ashman, P.J., Sathe, S., Lewis, D.M., 2013. Harvesting, Thickening and Dewatering Microalgae Biomass. In: Michael A., B., Navid R., M. (Eds.), Algae for Biofuels and Energy. Springer Netherlands, Dordrecht, pp. 165-185.

Park, J.B.K., Craggs, R.J., Shilton, A.N., 2011. Wastewater treatment high rate algal ponds for biofuel production. Bioresource Technology 102, 35-42.

Park, J.B.K., Craggs, R.J., Shilton, A.N., 2015. Algal recycling enhances algal productivity and settleability in Pediastrum boryanum pure cultures. Water Research 87, 97-104.

Poelman, E., Depauw, N., Jeurissen, B., 1997. Potential of electrolytic flocculation for recovery of micro-algae. Resources, Conservation and Recycling 19, 1-10.

Posadas, E., Bochon, S., Coca, M., García-González, M.C., García-Encina, P. a., Muñoz, R., 2014. Microalgae-based agro-industrial wastewater treatment: a preliminary screening of biodegradability. Journal of Applied Phycology.

Rickman, M., Pellegrino, J., Davis, R., 2012. Fouling phenomena during membrane filtration of microalgae. Journal of Membrane Science 423-424, 33-42.

Roselet, F., Burkert, J., Abreu, P.C., 2016. Flocculation of Nannochloropsis oculata using a tannin-based polymer: Bench scale optimization and pilot scale reproducibility. Biomass and Bioenergy 87, 55-60.

Roselet, F., Vandamme, D., Roselet, M., Muylaert, K., Cesar, P., 2015. Screening of commercial natural and synthetic cationic polymers for $\mathrm{fl}$ occulation of freshwater and marine microalgae and effects of molecular weight and charge density. Algal research 10, 183-188.

Rossignol, N., Vandanjon, L., Jaouen, P., Quéméneur, F., 1999. Membrane technology for the continuous separation microalgae/culture medium: compared performances of cross-flow microfiltration and ultrafiltration. Aquacultural Engineering 20, 191-208.

Salim, S., Kosterink, N.R., Wacka, N.D.T., Vermuë, M.H., Wijffels, R.H., 2014. Mechanism behind autoflocculation of unicellular green microalgae Ettlia texensis. Journal of biotechnology 1-5. 
Salim, S., Vermuë, M.H., Wijffels, R.H., 2012. Ratio between autoflocculating and target microalgae affects the energy-efficient harvesting by bio-flocculation. Bioresource Technology 118, 49-55.

Sandbank, E., Shelef, G., 1987. Harvesting of Algae From High Rate Ponds By Flocculation-Flotation. Water Science \& Technology 19, 257-263.

Shelef, G., Sukenik, A., Green, M., 1984. Microalgae harvesting and processing: a literature review, Program No. SERI/STR-231-2396. Technion Research and Development Foundation Ltd., Haifa (Israel).

Şirin, S., Trobajo, R., Ibanez, C., Salvadó, J., 2012. Harvesting the microalgae Phaeodactylum tricornutum with polyaluminum chloride, aluminium sulphate, chitosan and alkalinity-induced flocculation. Journal of Applied Phycology 24, 1067-1080.

Smith, B.T., Davis, R.H., 2012. Sedimentation of algae flocculated using naturallyavailable, magnesium-based flocculants. Algal Research 1, 32-39.

Smith, B.T., Davis, R.H., 2013. Particle concentration using inclined sedimentation via sludge accumulation and removal for algae harvesting. Chemical Engineering Science 91, 79-85.

Spilling, K., Seppälä, J., Tamminen, T., 2011. Inducing autoflocculation in the diatom Phaeodactylum tricornutum through $\mathrm{CO} 2$ regulation. Journal of Applied Phycology 23, 959-966.

Thomassen, G., Egiguren Vila, U., van Dael, M., Lemmens, B., van Passel, S., 2016. A techno-economic assessment of an algal-based biorefinery. Clean Technologies and Environmental Policy 1-14.

Uduman, N., Bourniquel, V., Danquah, M.K., Hoadley, A.F. a., 2011. A parametric study of electrocoagulation as a recovery process of marine microalgae for biodiesel production. Chemical Engineering Journal 174, 249-257.

Uduman, N., Qi, Y., Danquah, M.K., Forde, G.M., Hoadley, A., 2010. Dewatering of microalgal cultures: A major bottleneck to algae-based fuels. Journal of Renewable and Sustainable Energy 2, 012701.

Van Den Hende, S., Vervaeren, H., Desmet, S., Boon, N., 2011. Bioflocculation of microalgae and bacteria combined with flue gas to improve sewage treatment. New biotechnology 29, 23-31.

Vandamme, D., Beuckels, A., Markou, G., Foubert, I., Muylaert, K., 2015. Reversible Flocculation of Microalgae using Magnesium Hydroxide. BioEnergy Research 8, 716-725.

Vandamme, D., Beuckels, A., Vadelius, E., Depraetere, O., Noppe, W., Dutta, A., Foubert, I., Laurens, L., Muylaert, K., 2016. Inhibition of alkaline flocculation by algal organic matter for Chlorella vulgaris. Water Research 88, 301-307.

Vandamme, D., Foubert, I., Fraeye, I., Meesschaert, B., Muylaert, K., 2012. Flocculation of Chlorella vulgaris induced by high $\mathrm{pH}$ : role of magnesium and calcium and practical implications. Bioresource technology 105, 114-9.

Vandamme, D., Foubert, I., Meesschaert, B., Muylaert, K., 2010. Flocculation of microalgae using cationic starch. Journal of Applied Phycology 22, 525-530. 
Vandamme, D., Foubert, I., Muylaert, K., 2013. Flocculation as a low-cost method for harvesting microalgae for bulk biomass production. Trends in biotechnology 31, 233-9.

Vandamme, D., Muylaert, K., Fraeye, I., Foubert, I., 2014. Floc characteristics of Chlorella vulgaris: Influence of flocculation mode and presence of organic matter. Bioresource Technology 151, 383-387.

Vandamme, D., Pontes, S.C. V., Goiris, K., Foubert, I., Pinoy, L.J.J., Muylaert, K., 2011. Evaluation of electro-coagulation-flocculation for harvesting marine and freshwater microalgae. Biotechnology and Bioengineering 108, 2320-2329.

Wang, Z., Hou, J., Bowden, D., Belovich, J.M., 2014. Evaluation of an inclined gravity settler for microalgae harvesting. Journal of Chemical Technology \& Biotechnology 89, 714-720.

Wijffels, R.H., Barbosa, M.J., 2010. An outlook on microalgal biofuels. Science 329, 796-9.

Wyatt, N.B., Gloe, L.M., Brady, P. V., Hewson, J.C., Grillet, A.M., Hankins, M.G., Pohl, P.I., 2012. Critical conditions for ferric chloride-induced flocculation of freshwater algae. Biotechnology and bioengineering 109, 493-501.

Xu, L., Guo, C., Wang, F., Zheng, S., Liu, C., 2011. A simple and rapid harvesting method for microalgae by in situ magnetic separation. Bioresource Technology 102, 10047-51.

Xu, L., Wang, F., Li, H.-Z., Hu, Z.-M., Guo, C., Liu, C.-Z., 2010. Development of an efficient electroflocculation technology integrated with dispersed-air flotation for harvesting microalgae. Journal of Chemical Technology \& Biotechnology 85, 1504-1507.

Yang, J., Xu, M., Zhang, X., Hu, Q., Sommerfeld, M., Chen, Y., 2011. Life-cycle analysis on biodiesel production from microalgae: water footprint and nutrients balance. Bioresource technology 102, 159-65.

Zhang, X., Amendola, P., Hewson, J.C., Sommerfeld, M., Hu, Q., 2012. Influence of growth phase on harvesting of Chlorella zofingiensis by dissolved air flotation. Bioresource technology 116, 477-84.

Zhou, W., Min, M., Hu, B., Ma, X., Liu, Y., Wang, Q., Shi, J., Chen, P., Ruan, R., 2013. Filamentous fungi assisted bio-flocculation: A novel alternative technique for harvesting heterotrophic and autotrophic microalgal cells. Separation and Purification Technology 107, 158-165. 
Vandamme, D., Foubert, I., Muylaert, K., 2013. Flocculation as a low-cost method for harvesting microalgae for bulk biomass production. Trends in biotechnology 31, 233-9.

Vandamme, D., Muylaert, K., Fraeye, I., Foubert, I., 2014. Floc characteristics of Chlorella vulgaris: Influence of flocculation mode and presence of organic matter. Bioresource Technology 151, 383-387.

Vandamme, D., Pontes, S.C. V., Goiris, K., Foubert, I., Pinoy, L.J.J., Muylaert, K., 2011. Evaluation of electro-coagulation-flocculation for harvesting marine and freshwater microalgae. Biotechnology and Bioengineering 108, 2320-2329.

Wang, Z., Hou, J., Bowden, D., Belovich, J.M., 2014. Evaluation of an inclined gravity settler for microalgae harvesting. Journal of Chemical Technology \& Biotechnology 89, 714-720.

Wijffels, R.H., Barbosa, M.J., 2010. An outlook on microalgal biofuels. Science 329, 796-9.

Wyatt, N.B., Gloe, L.M., Brady, P. V., Hewson, J.C., Grillet, A.M., Hankins, M.G., Pohl, P.I., 2012. Critical conditions for ferric chloride-induced flocculation of freshwater algae. Biotechnology and bioengineering 109, 493-501.

Xu, L., Guo, C., Wang, F., Zheng, S., Liu, C., 2011. A simple and rapid harvesting method for microalgae by in situ magnetic separation. Bioresource Technology 102, 10047-51.

Xu, L., Wang, F., Li, H.-Z., Hu, Z.-M., Guo, C., Liu, C.-Z., 2010. Development of an efficient electroflocculation technology integrated with dispersed-air flotation for harvesting microalgae. Journal of Chemical Technology \& Biotechnology 85, 1504-1507.

Yang, J., Xu, M., Zhang, X., Hu, Q., Sommerfeld, M., Chen, Y., 2011. Life-cycle analysis on biodiesel production from microalgae: water footprint and nutrients balance. Bioresource technology 102, 159-65.

Zhang, X., Amendola, P., Hewson, J.C., Sommerfeld, M., Hu, Q., 2012. Influence of growth phase on harvesting of Chlorella zofingiensis by dissolved air flotation. Bioresource technology 116, 477-84.

Zhou, W., Min, M., Hu, B., Ma, X., Liu, Y., Wang, Q., Shi, J., Chen, P., Ruan, R., 2013. Filamentous fungi assisted bio-flocculation: A novel alternative technique for harvesting heterotrophic and autotrophic microalgal cells. Separation and Purification Technology 107, 158-165. 
A

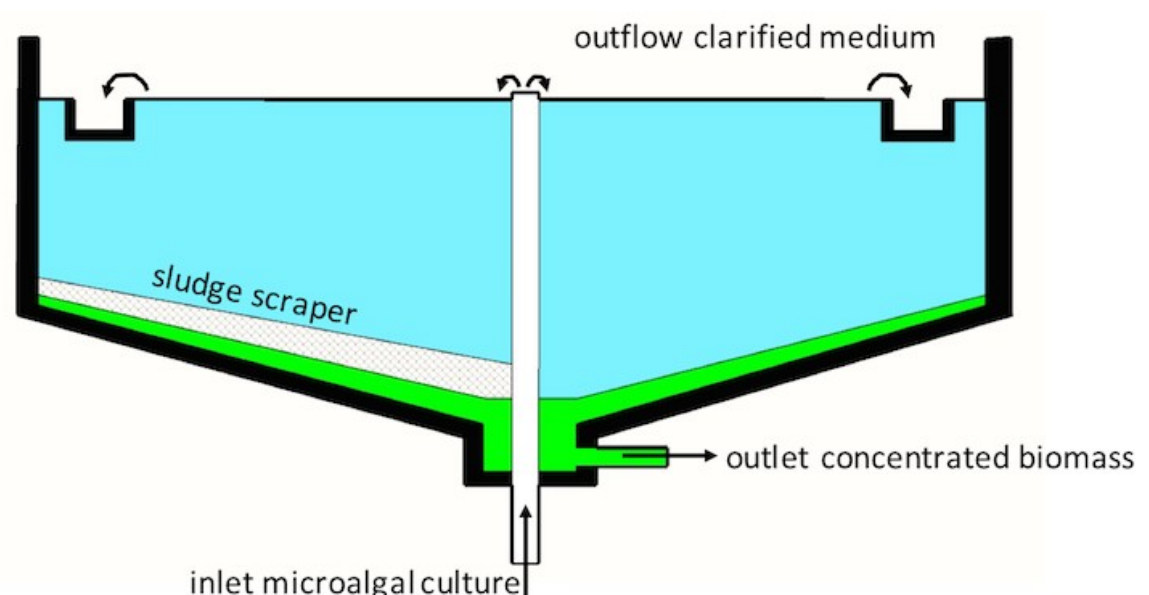

B

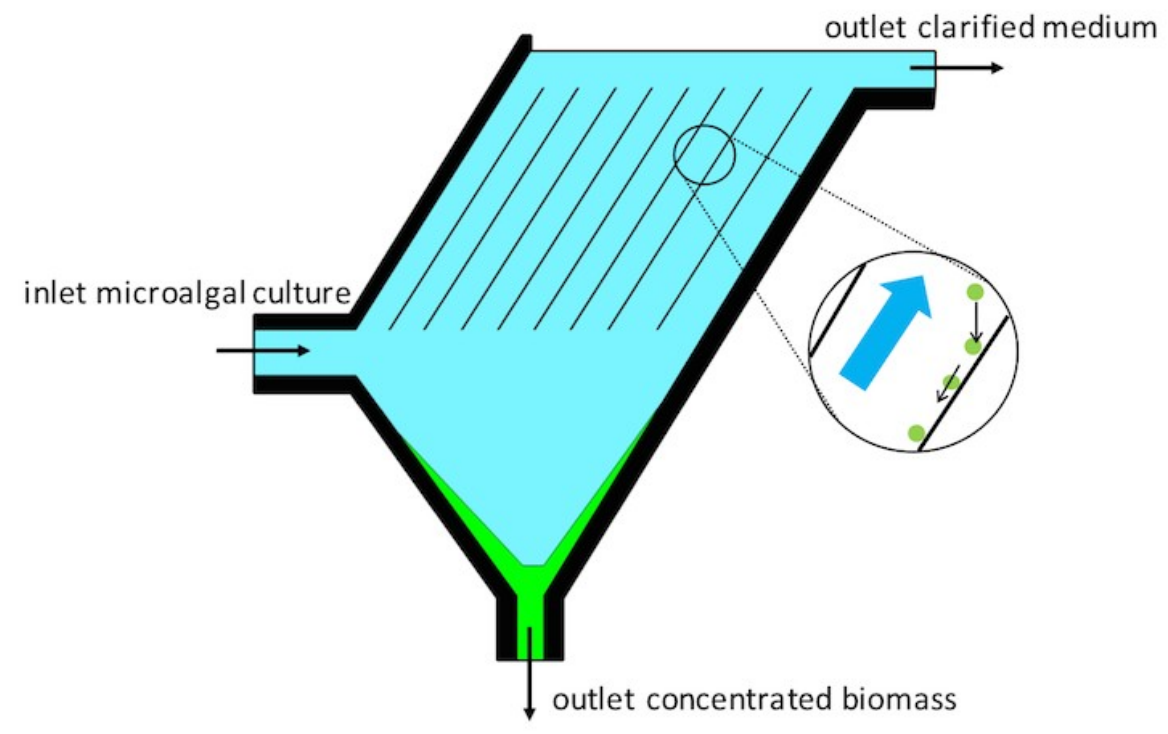

C

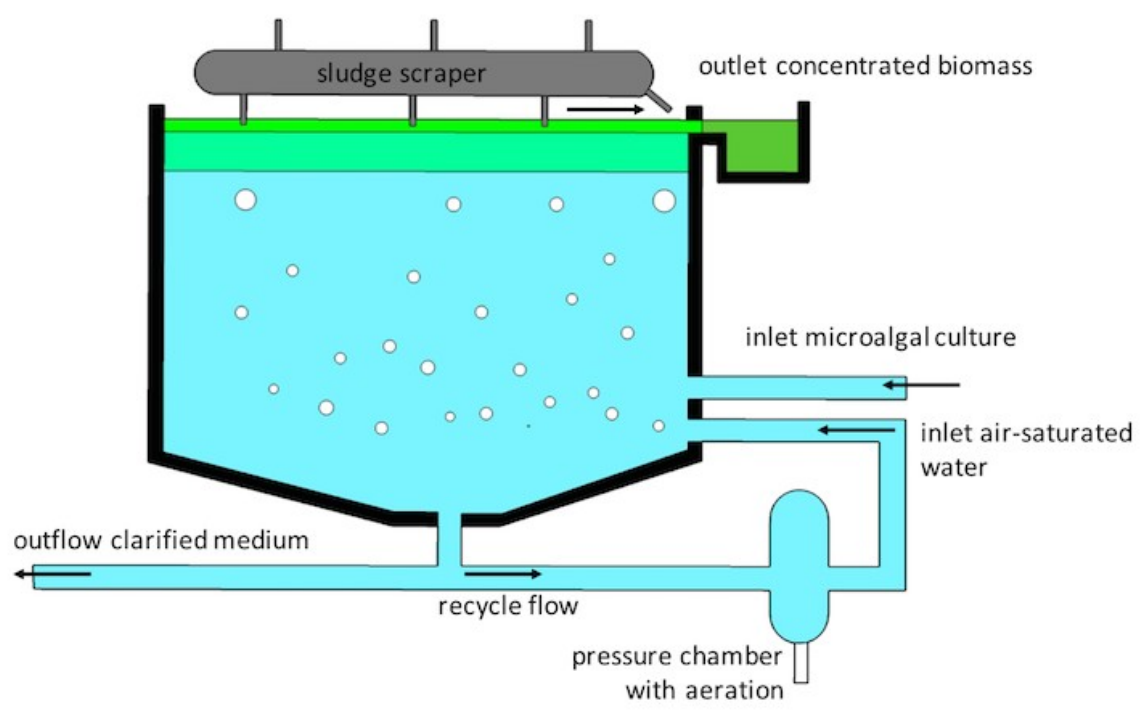




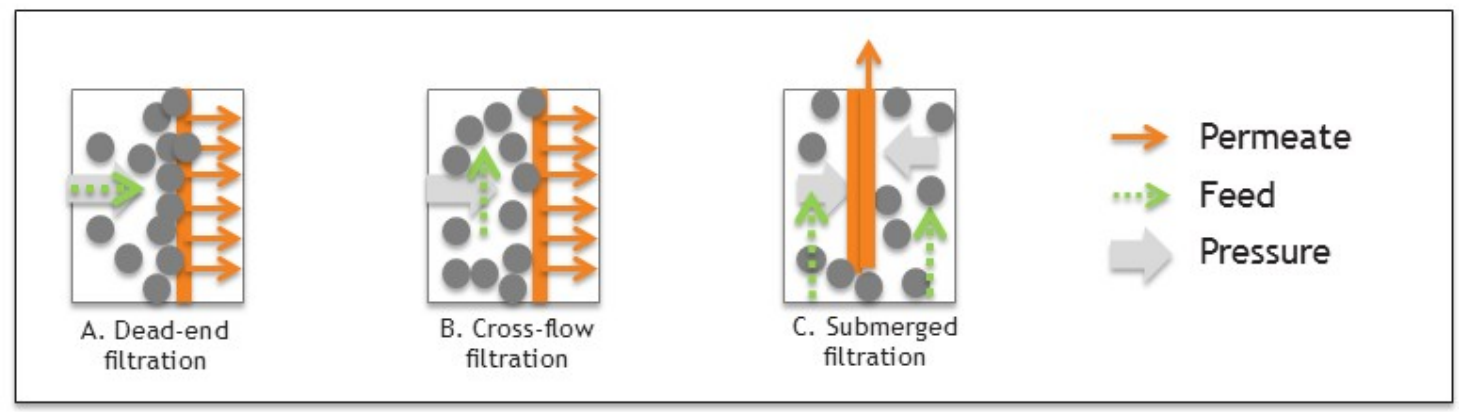

